\title{
High Prevalence of Giardiasis and Strongyloidiasis Among HIV-Infected Patients in Bahia, Brazil
}

Giovana Feitosa, Antônio C. Bandeira, Diana P. Sampaio, Roberto Badaró and Carlos Brites
University Hospital Professor Edgar Santos, Federal University of Bahia, Brazil

\begin{abstract}
Diarrhea due to intestinal microbial infections is a frequent manifestation among $\mathrm{HIV}$-infected patients. It has been postulated that HIV-infected patients may have special types of intestinal infections, and that immune activation from such parasites may affect the progression of HIV disease. To evaluate these associations, the frequency of infections was examined in $\mathrm{HIV}$-infected patients in Bahia, Brazil. To determine the potential impact of the presence of intestinal parasitic infections on HIV disease progression, a retrospective study approach was used. The medical charts of 365 HIV-infected patients who had been treated at the AIDS Clinic of the Federal University of Bahia Hospital were reviewed, and the prevalence of parasites was compared with 5,243 HIV-negative patients who had attended the hospital during the same period of time. Among HIV-infected subjects, $C_{4}$ count, RNA plasma viral load (VL), and number of eosinophils were compared according to their stool examination results. The overall prevalence of each parasite was similar for HIV-positive and HIV-negative patients. However, the prevalence of $S$. stercoralis $\left(\mathrm{p}<10^{-7}\right)$ and $\mathrm{G}$. Iamblia $(\mathrm{p}=\mathbf{0 . 0 0 5})$ was greater for $\mathrm{HIV}$-infected subjects. The mean $\mathrm{CD}_{4}$ count and viral load of HIV patients in our clinic who had stool examinations was 350 cells \pm 340 and $4.4 \pm$ $1.4 \log$ RNA viral load, respectively. In this patient group there was no clear association between the level of the absolute $\mathrm{CD}_{4}$ count or the viral load and a specific parasitic infection. The presence of an intestinal parasitic infection was not associated with faster progression of the HIV disease among HIV-infected patients. We conclude that strongyloidiasis and giardiasis are more frequent in HIV-infected patients in Bahia, Brazil. If this association is due to immune dysregulation, as has been proposed elsewhere, it must occur in patients after only minor shifts in $\mathrm{CD}_{4}$ count from normal levels, or as a result of immune dysfunction not represented by $\mathrm{CD}_{4}$ count. These infections do not appear to alter the progression of HIV disease.
\end{abstract}

Key Words: HIV-infected patients, strongyloidiasis, giardiasis.

Diarrhea is one of the most prevalent manifestations of disease among AIDS patients [1]. Such a high frequency of diarrhea is basically associated with the

Received on 9 July 2001; revised 14 November 2001.

Address for correspondence: Dr. Carlos Brites. Hospital Universitário Prof. Edgard Santos, $6^{\circ}$. andar. Rua João das Botas, SN, Canela - Salvador, Bahia, Brazil-Zip Code:: 40.110160. Phone number: 55-71-235-4901; Fax number: 55-71-2472756. E-mail: crbrites@ufba.br.

This work was partially presented at the XIII International AIDS Conference, in Durban, South Africa (poster WePeC4450).

The Brazilian Journal of Infectious Diseases 2001;5(6):339-344. (C) 2001 by The Brazilian Journal of Infectious Diseases and Contexto Publishing. All rights reserved.

$1413-8670$ presence of intestinal parasites, and the identification of infections caused by Isospora belli and Cryptosporidium sp. are considered AIDS diagnostic events [2,3]. On the other hand, common intestinal pathogens are also diagnosed frequently among HIVinfected subjects, mostly in the developing world [37]. In Brazil, there have only seen a few reports about the prevalence of intestinal parasites and worms among HIV-infected patients.

There is some controversy about the potential effects of co-infection by intestinal worms on HIV disease. Some authors suggest that it could be an important factor of immune activation in this population, leading to a faster disease progression as a result of such interaction [8]. Immunological evaluation of a group of 
HIV-negative Ethiopians, who migrated to Israel, showed strong evidence in favor of immune dysregulation; if this were to occur in HIV-positive patients, one could predict the faster progression of HIV disease in these patients [8-10]. Since intestinal parasites can cause immune activation, the high prevalence of intestinal parasites could be a factor involved in AIDS progression among African patients [8-12].

We conducted this study to evaluate the frequency of common intestinal parasites among HIV-infected patients in Bahia, Brazil. In addition, we evaluated the association between the presence of parasites in their stools, the level of $\mathrm{CD}_{4}^{+}$cells, and plasma RNA viremia among these subjects.

\section{Materials and Methods}

Subjects: The medical charts of 690 HIV infected patients attended at the AIDS Clinic of Professor Edgard Santos University Hospital (HUPES) at the Federal University of Bahia, Brazil, from January, 1997, to June, 1999, were reviewed. All patients had HIV infection confirmed by Western blot. Demographic data, $\mathrm{CD}_{4}^{+}$cell count $\left(\mathrm{CD}_{4}\right)$, and HIV-1 RNA plasma viral load (VL) were recorded, as well as the frequency and results of stool examinations performed during that time interval. In addition, presence of gastrointestinal symptoms and white blood cell (WBC) results were recorded. For purpose of analysis, we considered the values of $\mathrm{CD}_{4}$ and $\mathrm{VL}$ performed at the time closest to stools examination. We also randomly selected approximately 7,000 (each third) stool examinations from a total of 21,000 tests performed at the HUPES, corresponding to 5,243 HIV negative patients, during the same period of time.

Laboratory methods: RNA VL was assessed in all patients by Nuclisens (Organon Teknika, Boxtel, Holland), with a lower detection limit of 40 HIV-RNA copies $/ \mathrm{ml}$. Determination of $\mathrm{CD}_{4}$ count was performed by flow cytometry. Analysis of fecal specimens is routinely done according to the methods of Hoffmann,
Faust, and Baermann (when indicated by physicians). Detection of opportunistic pathogens was attempted by modified acid-fast staining.

Statistical analysis: Two different analyses were performed. First, we compared only the prevalence rate for HIV-positive and HIV-negative subjects. Patients were not paired according to age and/or sex, since this information was not available for HIVnegative controls. Second, we compared the overall prevalence and the specific prevalence for each parasite among HIV-infected patients.

A comparison of $\mathrm{CD}_{4}, \mathrm{VL}$, absolute $\mathrm{WBC}$, and eosinophils was done for HIV-infected individuals according to the presence of any intestinal parasite and for each detected worm, specifically. Means were compared using analysis of variance. Proportion was evaluated by chi-square test. Logistic regression analysis was performed to assess the relationship between $\mathrm{CD}_{4}, \mathrm{VL}$, and the presence of intestinal parasites.

Viral load measures were transformed to logarithmic values and used in analytical procedures. Initially, absolute $\mathrm{CD}_{4}$ cell counts were compared; the counts were stratified in two levels $\left(\geq 200 \mathrm{CD}_{4}^{+}\right.$cells or $\leq 200 \mathrm{CD}_{4}^{+}$cells) and treated as a dummy variable. Fisher's exact test was used when testing differences in qualitative variable distributions. Student's T test was used when testing differences in quantitative variables among groups. An alfa level of 0.05 was arbitrarily chosen. Statistical 4.0 for Windows and StatXact-3 were used for computational and statistical procedures.

\section{Results}

A total of 1,043 medical charts of HIV-positive patients were reviewed, corresponding to the total number of subjects attended at the HUPES AIDS Clinics from January, 1997, though June, 1999. From this group, a total of 690 patients were followed for at least 6 months, and 365 subjects had at least one stool examination recorded. 
For HIV-negative controls, we randomly selected a sample of 5,243 stool examinations performed on HIV-negative individuals, from a total of 20,972 tests performed during that time period.

Table 1 shows the prevalence of nonopportunistic intestinal parasites diagnosed, according to the HIV serological status. The overall prevalence of any parasites was similar for both HIV-positive and HIV-negative patients, but Giardia lamblia $(\mathrm{p}=0.005)$ and Strongyloides stercoralis $\left(\mathrm{p}<10^{-7}\right)$ were significantly associated with HIV infection. Entamoeba coli $(\mathrm{p}=0.0002)$ and Endolimax nana $(\mathrm{p}=0.004)$ were less frequently diagnosed among HIV-positive patients. Stool test results revealed that 105 $(64 \%)$ individuals had only 1 diagnosed parasite, while $40(25 \%)$ had 2 parasites, $13(8 \%)$ had 3 parasites, $4(2 \%)$ had 4 parasites, and 1 patient had 6 different parasites detected.

As expected, patients with at least 1 diagnosed parasite had a higher number of stool samples tested. Mean age, frequency of gender, absolute WBC, absolute eosinophils count, and presence of gastrointestinal symptoms were similar for HIVpositive and HIV-negative groups (Table 2). However, we did observe a trend for lower mean age among patients harboring G. lamblia $(25.7$ years vs. 33.2 years; $p=0.057$ ). We did not detect any difference when comparing means of absolute $\mathrm{CD}_{4}$ cell counts and presence of a diagnosed parasite, in general, or any parasite in particular (Table 3). However, when stratified into 2 groups, we found an association between higher $\mathrm{CD}_{4}$ counts $(>200)$ and presence of at least 1 parasite (prevalence of $66 \%$ and $51 \%$ for higher and lower $\mathrm{CD}_{4}$ counts, respectively, $\mathrm{p}<0.01$ ). In addition, a univariate analysis showed a lower viral load for patients presenting any diagnosed parasites $(\mathrm{p}=0.02)$ but, after controlling for $\mathrm{CD}_{4}$ levels, the difference disappeared. However, patients harboring Entamoeba histolytica maintained a significantly lower viral load $(\mathrm{p}=0.01)$ and a trend to a higher $\mathrm{CD}_{4}>200$ count $(\mathrm{p}=0.06)$.

\section{Discussion}

Diarrhea is a common manifestation of disease among AIDS patients in Brazil: a previous study showed that diarrhea was diagnosed in $70 \%$ of symptomatic individuals attended at HUPES [3]. However, there is scarce information about the prevalence of common intestinal worms in this population. This study evaluated the prevalence of intestinal parasites in AIDS patients, comparing this group with other ofHIV-negative subjects tested during the same time period at the same laboratory. Our findings showed similar prevalence of parasites for both groups (HIV-infected/non-infected), but S. stercoralis and $G$. lamblia were significantly more prevalent among HIV-infected individuals than among negative controls. On the other hand, non-pathogenic agents such $E$. nana and E. coli were associated with absence of HIV infection. Of note, the prevalence we found was similar to that found in previous work in Bahia, by Moreira, et al., but it was lower than that observed by Moura in Rio de Janeiro, Brazil [3,14].

Several reports on the interaction between HIV and enteric parasites showed a significant association between $S$. stercoralis and HIV infection [5,15-17]. However, this association is not observed consistently for other parasites: in a study conducted among sugarestate residents in Ethiopia, Fontanet, et al. found a higher prevalence of amoebic parasites in HIV patients than in negative patients [13]. Also, Mendez, et al. detected a positive association between HIV infection and E. histolytica, and I. bütschlii, in Buenos Aires [6]; while Lindo, et al. found an association between S. stercoralis and HIV infection, but a lower risk for infestation by $G$. lamblia, A. lumbricoides and $T$. trichiurus, in Honduras [5].

It seems clear that there is no standard pattern of occurrence of parasites among AIDS patients. The prevalence rate of a specific parasite may vary from country to country, and even from different regions in the same country $[3-5,12,14,21,22]$. Variation in the designs of such studies make a direct comparison between the results impossible. Nevertheless, the association between $S$. stercoralis and HIV infection 
Table 1. Prevalence of intestinal parasites according to HIV infection status

\begin{tabular}{lrccc}
\hline Intestinal parasites & $\begin{array}{c}\text { HIV+(\%) } \\
\mathbf{n}=\mathbf{3 6 5}\end{array}$ & $\begin{array}{c}\text { HIV-(\%) } \\
\mathbf{n}=\mathbf{5 , 2 4 3}\end{array}$ & OR (95\% CI) & p value \\
\hline Any & $161(44.1 \%)$ & $2,478(47.3 \%)$ & $0.88(0.71-1.1)$ & $\mathrm{NS}$ \\
E. nana & $69(18.9 \%)$ & $1,349(25.7 \%)$ & $0.67(0.51-0.89)$ & 0,004 \\
E. coli & $29(7.9 \%)$ & $801(15.3 \%)$ & $0.48(0.32-0.71)$ & 0,0002 \\
A. lumbricoides & $43(11.8 \%)$ & $495(94 \%)$ & $1.28(0.98-1.80)$ & $\mathrm{NS}$ \\
T. trichiurus & $19(5.2 \%)$ & $291(5.5 \%)$ & $0.93(0.56-1.54)$ & $\mathrm{NS}$ \\
E. hystolytica & $20(5.5 \%)$ & $215(4.1 \%)$ & $1.36(0.82-2.21)$ & $\mathrm{NS}$ \\
A. duodenalis & $16(4.4 \%)$ & $198(3.8 \%)$ & $1.17(0.87-2.01)$ & $\mathrm{NS}$ \\
G. lamblia & $18(4.9 \%)$ & $127(2.4 \%)$ & $2.2(1.23-3.59)$ & 0,005 \\
I. butschlii & $4(1.1 \%)$ & $93(1.8 \%)$ & $0.61(0.19-1.79)$ & $\mathrm{NS}$ \\
S. mansoni & $9(2.5 \%)$ & $78(1.5 \%)$ & $1.67(0.78-3.48)$ & $\mathrm{NS}$ \\
S. stercoralis & $20(5.5 \%)$ & $39(0.74 \%)$ & $7.74(4.3-13.8)$ & $<10^{-7}$ \\
E. vermicularis & $2(0.5 \%)$ & $56(1.1 \%)$ & $0.51(0.09-2.14)$ & $\mathrm{NS}$ \\
H. nana & $1(0.3 \%)$ & $16(0.3 \%)$ & $0.9(0.12-6.78)$ & $\mathrm{NS}$ \\
\hline
\end{tabular}

$\mathrm{NS}=\mathrm{p}$ value $>0.05$.

Table 2. Characteristics of HIV-infected patients according to the presence or absence of diagnosed intestinal parasites

\begin{tabular}{lccc}
\hline & $\begin{array}{c}\text { At least 1 } \\
\text { parasite (n) }\end{array}$ & $\begin{array}{c}\text { No diagnosed } \\
\text { parasite (n) }\end{array}$ & p value \\
\hline Age & $32.7 \pm 12$ & $33.35 \pm 12$ & 0.15 \\
Gender & & & \\
$\quad$ male & $100(43 \%)$ & $130(57 \%)$ & 0.6 \\
$\quad$ female & $52(46 \%)$ & $60(54 \%)$ & \\
Absolute WBC & $5.647 \pm 2.387$ & $5.657 \pm 2511$ & 0.9 \\
Eosinophilis (\%) & $7.9 \pm 7.7$ & $7.2 \pm 6.8$ & 0.54 \\
GI symptoms & & & \\
$\quad$ Yes & $74(44 \%)$ & $96(56 \%)$ & 0.8 \\
$\quad$ No & $86(45 \%)$ & $107(55 \%)$ & 0.01 \\
Number of stools samples & $1.8 \pm 1.1$ & $1.6 \pm 1.0$ & \\
examined (mean \pm sd $)$ & & & \\
\hline GI $=$ gastrointestinal. & & &
\end{tabular}


Table 3. $\mathrm{CD}_{4}$ level and HIV RNA plasma viral load of patients according to the presence of intestinal parasites (means $\pm \mathrm{SD}$ )

\begin{tabular}{|c|c|c|c|c|c|c|}
\hline \multirow[b]{2}{*}{ Parasites identified } & \multicolumn{3}{|c|}{$\mathrm{CD}_{4}$ levels (means $\left.\pm \mathrm{SD}\right)$} & \multicolumn{3}{|c|}{ Viral load $\left(\log _{10}\right.$ RNA copies $\left./ \mathrm{ml}\right)$} \\
\hline & Yes & No & $\begin{array}{c}\mathbf{p} \\
\text { value }\end{array}$ & Yes & No & $\begin{array}{c}\mathbf{p} \\
\text { value }\end{array}$ \\
\hline ANY & $396 \pm 340$ & $336 \pm 330$ & 0.1 & $4.3 \pm 1.0$ & $4.5 \pm 1.4$ & $0.02 *$ \\
\hline A. duodenalis & $277 \pm 306$ & $367 \pm 337$ & 0.3 & $4.8 \pm 1.2$ & $4.4 \pm 1.1$ & 0.58 \\
\hline A. lumbricoides & $370 \pm 289$ & $362 \pm 342$ & 0.9 & $4.2 \pm 1.0$ & $4.5 \pm 1.2$ & 0.07 \\
\hline E. coli & $407 \pm 260$ & $360 \pm 341$ & 0.8 & $4.3 \pm 0.9$ & $4.5 \pm 1.2$ & 0.14 \\
\hline E. vermicolaris & $262 \pm 305$ & $364 \pm 336$ & 0.7 & $4.0 \pm 1.4$ & $4.5 \pm 1.1$ & 0.41 \\
\hline G. lamblia & $482 \pm 516$ & $357 \pm 323$ & 0.3 & $4.5 \pm 1.3$ & $4.4 \pm 1.1$ & 0.92 \\
\hline E. hystolytica & $427 \pm 302$ & $359 \pm 337$ & 0.4 & $4.0 \pm 1.0$ & $4.5 \pm 1.1$ & 0.012 \\
\hline E. nana & $399 \pm 351$ & $355 \pm 332$ & 0.5 & $4.4 \pm 1.1$ & $4.5 \pm 1.2$ & 0.25 \\
\hline I. butschlii & $329 \pm 135$ & $364 \pm 337$ & 0.8 & $3.5 \pm 0.6$ & $4.5 \pm 1.1$ & 0.04 \\
\hline S. mansoni & $234 \pm 225$ & $367 \pm 337$ & 0.2 & $4.3 \pm 1.3$ & $4.5 \pm 1.1$ & 0.91 \\
\hline S. stercoralis & $356 \pm 326$ & $480 \pm 452$ & 0.3 & $4.9 \pm 1.3$ & $4.4 \pm 1.1$ & 0.19 \\
\hline T. trichiurus & $407 \pm 226$ & $361 \pm 340$ & 0.6 & $4.3 \pm 1.0$ & $4.5 \pm 1.2$ & 0.26 \\
\hline H. nana & $390 \pm 0$ & $363 \pm 336$ & 0.94 & $3.0 \pm 0$ & $4.5 \pm 1.1$ & 0.23 \\
\hline
\end{tabular}

$* \mathrm{p}$ value $>0.05$ after controlling for $\mathrm{CD}_{4}$ count.

seems consistent and is the only common conclusion of the majority of the studies [5,12,15-17]. Of note, both Strongiloidiasis and giardiasis have been found in patients with immunologic dysfunction other than HIV infection.

Another question concerns the effects of parasitic infection on HIV disease. Although some in vitro evidence suggests that a immune activation may be a consequence of parasitic infection, the eventual impact on HIV progression remains an unanswered question. Shapira-Nahor, et al. showed an increased susceptibility of PBMC from chronically immune activated individuals to HIV-infection, and hypothesized it could be a result of chronic parasitic infection [11]. For example, the effects of nematode infection on immune systems of HIV-negative individuals induces an impaired Th1 response and seems to be dependent on cytokine balance $(23,25)$. However, we cannot rule out other potential causes of such activation, like other infectious diseases. Bentwich agrees with that point of view, but also recognizes that other factors could play a role in immune activation in such population [8-11].

The laboratory results we found in this study show a similar immunological pattern for HIV-infected patients, regardless of the stool examination results. We observed no difference between age, gender, absolute WBC, eosinophils and $\mathrm{CD}_{4}$ counts for both groups. The mean eosinophil count was above the normal value for both groups, but this finding is probably a result of the immune dysregulation caused by HIV, and not a consequence of parasiticinfection. However, mean viral load was significantly lower for patients with at least 1 parasite infection and, specifically, for patients harboring $E$. histolityca, even after controlling for $\mathrm{CD}_{4}$ counts. Thus, in our study, we did not detect any association between intestinal parasites and evidence ofHIV disease progression.

The significance of a higher prevalence of nonpathogenic protozoa like E. coli and E. nana among HIV-negative individuals, compared to infected patients is not clear. We can only hypothesize that HIV 
may cause changes in the bowel environment, making it unfavorable to such organisms. However, the limited information provided by this study does not provide support for this conclusion.

\section{References}

1. Bartlett I.G., Belitsos P.C., Sears C.L. AIDS enteropathy. Clin Infect Dis 1992;15:979-82.

2. CDC Revision Case Definition for AIDS. MMWR 41: RR17, Dec. 18, 1992.

3. Moreira J.D.E., Silva N., Brites C., Johnson Warren D. Jr. Characteristics of the acquired immunodeficiency syndrome in Brazil. Am J Trop Med Hyg 1993;48:687-92.

4. Germani Y., Minssart P., Vohito M., et al. Etiologies of acute, persistent, and dysenteric diarrheas in adults in Bangui, Central African Republic, in relation to human immunodeficiency virus serostatus. Am J Trop Med Hyg 1998;59:1008-14.

5. Lindo J.E., Dubon J.M., Ager A., Palmer C. Intestinal parasitic infections in human immunodeficiency virus (HIV)- positive and HIV-negative individuals in San Pedro Sula, Honduras. Am J Trop Med Hyg 1998;58:43 1-5.

6. Mendez O.C., Szmulewicz G., Gatta C. Comparison of intestinal parasite infestation indexes among HIV positive and negative populations. Medicina 1994;54(4):307-10.

7. Cotte L., Raodonirina M., Trepo C. Prevalence of intestinal protozoans in French patients infected with HIV. J Acquir Immune Defic Syndr 1993;6(9):1024-9.

8. Bentwich Z., Kalinkovich A., Weisman Z. Immune activation is a dominant factor in the pathogenesis of African AIDS. Immunol Today 1995; 16:187-91.

9. Bentwich Z., Weisman Z., Kalinkovich A. Immune dysregulation in Ethiopian immigrants in Israel: relevance to helminth infection. Clin Exp Immunol 1996;103:239-43.

10. Weisman Z., Kalinkovich A., Bentwich Z. Infection by different HIV-1 subtypes (B and C) results in a similar immune activation profile despite distinct immune backgrounds. J AIDS 1999;21:157-63.

11. Shapira-Nahor, Kalinkovich A., Bentwich Z. Increased susceptibility to HIV-1 infection of peripheral blood mononuclear cells from chronically immune-activated individuals. AIDS 1998; 12:1731-3.

12. Bentwich Z., Kalinkovich A., Beyers A. Can erradication of helminthic infections change the face of AIDS and tuberculosis. Immunol Today 1999;20:485-7.
13. Fontanet A.L., Sahlu T., Rinke W.T., Coutinho R.A. Epidemiology of infection with intestinal parasites and human immunodeficiency virus (HIV) among sugarestate in Ethiopia. Ann Trop Med Parasitol 2000;94(3):269-78.

14. Moura H., Fernandes O., Villa J.P., Lima D.B. Enteric parasites and HIV infection: occurrence in AIDS patients in Rio de Janeiro, Brazil. Mem Inst Oswaldo Cruz 1989;84(4):527-33.

15. Cirioni O., Giacometti A., Scalise G. Strongyloides stercoralis first stage larvae in the lungs of a patient with AIDS: primary localization or a noninvasive form of dissemination? Clin Infect Dis 1996:22:737.

16. Nomura J., Rekrut K. Strongyloides stercoralis hyperinfection syndrome in a patient with AIDS: diagnosis by fluorescent microscopy. Clin Infect Dis 1996;22:736.

17. Guerin J.M., Leibinger F., Mofredj A. Strongyloides stercoralis infection in patients infected with human immunodeficiency virus. Clin Infect Dis 1997;24:95.

18. Galai N., Kalinkovich A., Bentwich Z. African HIV-1 subtype and rate of progression among Ethiopian immigrants in Israel. Lancet 1997;349:180-1.

19. Brandonisio O., Maggi P., Angarano G. Intestinal protozoa in HIV-infected patients in Apulia, South Italy. Epidemiol Infect 1999; 123(3):457-62.

20. Esfandiari A., Brown C.P. Prevalence of enteric parasitic infection among HIV-infected attendees of an inner city AIDS Clinic. Cell Mol Biol (Noisy-le-Grand) 1995;41:519-23.

21. Punpioworng B., Viriyavejakul P., Maneerat Y. Opportunistic protozoa in stool samples from HIVinfected patients. Southeast Asian J Trop Med Public Health 1998;29(1):31-4.

22. Esfandiari A., Swartaz J., Teklehaimanot S. Clustering of giardiasis among AIDS patients in Los Angeles County. Cell Mol Biol (Noisy-le grand) 1997;43(7):1077-83.

23. Bancroft A., Else K., Sypek J., Grencis R. Interleukin-12 promotes a chronic intestinal nematode infection. Eur J Immunol 1997;27:866-70.

24. Stadecker M.J., Hernandez H. The immune response and immunopathology in infection with Schistosoma mansoni: a key role of major egg antigen Sm-p40. Parasite Immunology 1998;20:217-21.

25. Sabin E., Araujo M.I., Pearce E. Impairment of tetanus toxoid-specific Th1-like immune responses in human infected with Schistosoma mansoni. J Inf Dis 1996; 173:269-72. 